\title{
Income disparities in life expectancy in the City of Toronto and Region of Peel, Ontario
}

\author{
J. Stratton, MHSc (1); D. L. Mowat, FRCPC (1,2,3,4); R. Wilkins, MUrb (5,6); M. Tjepkema, MPH (5)
}

This article has been peer reviewed.

\begin{abstract}
Introduction: To understand the lack of a gradient in mortality by neighbourhood income in a previous study, we used individual-level data from the 1991-2001 Canadian census mortality follow-up study to examine income-related disparities in life expectancy and probability of survival to age 75 years in the City of Toronto and Region of Peel.
\end{abstract}

Methods: We calculated period life tables for each sex and income adequacy quintile, overall and separately for immigrants and non-immigrants.

Results: For all cohort members of both sexes, including both immigrants and non-immigrants, there was a clear gradient across the income quintiles, with higher life expectancy in each successively richer quintile. However, the disparities by income were much greater when the analysis was restricted to non-immigrants. The lesser gradient for immigrants appeared to reflect the higher proportion of recent immigrants in the lower income quintiles.

Conclusion: These findings highlight the importance of using individual-level ascertainment of income whenever possible, and of including immigrant status and period of immigration in assessments of health outcomes, especially for areas with a high proportion of immigrants.

Keywords: cohort study, mortality, probability of survival, healthy immigrant effect, Canada

\section{Introduction}

The "income gradient in health," where health improves with each incremental increase in income, has been repeatedly demonstrated in both Canada and the United States, in studies of a variety of health outcomes including mortality, ${ }^{1,2}$ life expectancy, ${ }^{2}$ health-related quality of life $^{3}$ and disability. ${ }^{3,4}$ Those in a lower socio-economic position experience poorer health outcomes than their more affluent counterparts across a whole spectrum of measures. The socio-economic gradient is not static; it varies over time, by age and sex, as well as by the health measure and population subgroup studied.

In a recent small-area analysis that examined the relationship between life expectancy and neighbourhood income in the Region of Peel (immediately west of the City of Toronto), we used mortality data from the Ontario vital statistics mortality database for the year 2005, and 2006 census data on the census tract proportion of population with low income
(Appendix Table A). Our results showed that for both men and women, life expectancy was similar across all neighbourhood income quintiles-the expected gradient was clearly not present. We therefore undertook an analysis of previously linked census-mortality cohort data ${ }^{5}$ to help us understand how and why this was happening. We speculated that the high proportion of immigrants (49\%) who live in the region may have masked an income gradient in mortality due to the "healthy immigrant" effect. Moreover, because of the mixing of rich and poor in many neighbourhoods, neighbourhood averages misclassify many individuals, thus attenuating effect estimates. Studies in Canada and the United States have shown that the income gradient in mortality is more pronounced when data are analyzed by family income rather than by various measures of neighbourhood income. ${ }^{3-6}$ Previous studies of mortality among immigrants in Canada have either not dealt with differences across income groups ${ }^{7-11}$ or only adjusted for income or neighbourhood income (rather than explicitly showing results by income level). ${ }^{12-15}$

Our objectives were to report differences in all-cause mortality across income quintiles, using individual and family income derived from census microdata, and to examine how those differences varied among immigrants compared to non-immigrants. Using data from the 1991-2001 Canadian census mortality follow-up study, we calculated period life tables by sex for the combined area of the City of Toronto and Region of

\section{Author references:}

1. Peel Public Health, Brampton, Ontario, Canada

2. Dalla Lana School of Public Health, University of Toronto, Toronto, Ontario, Canada

3. Department of Community Health and Epidemiology, Queen's University, Kingston, Ontario, Canada

4. Faculty of Nursing, McMaster University, Hamilton, Ontario, Canada

5. Health Analysis Division, Statistics Canada, Ottawa, Ontario, Canada

6. Department of Epidemiology and Community Medicine, University of Ottawa, Ottawa, Ontario, Canada

Correspondence: Russell Wilkins, Health Analysis Division, Statistics Canada, RHC-24A, 100 Tunney’s Pasture Driveway, Ottawa, ON K1A 0T6; Tel.: (613) 951-5305; Fax: (613) 951-4936; Email: russell.wilkins@statcan.gc.ca 
Peel, by income adequacy quintile, for all cohort members as well as for immigrants and non-immigrants separately. Canadian data on all-cause mortality by individual or family income comparing results for immigrants and non-immigrants have not previously been published, and we hoped that the results would help us to better understand the findings of our previous study in this area.

\section{Methods}

\section{Data source}

The 1991-2001 Canadian census mortality follow-up study, conducted by Statistics Canada, is a probabilistically linked cohort database where a $15 \%$ sample ( $n=2735152$ ) of the non-institutional population aged 25 years or older who were enumerated by the 1991 census long-form questionnaire (the cohort) was linked to nearly 11 years of death records (from 4 June 1991 to 31 December 2001) from the Canadian mortality database. This linked file contains information on various demographic characteristics, socioeconomic position, activity limitations, and cause and date of any death. Additional details on the construction and contents of the linked file have previously been reported. ${ }^{5}$

For this study, data were extracted for the 1991 census divisions corresponding to the current Region of Peel (Mississauga, Brampton and Caledon) and the amalgamated City of Toronto (including the former cities of Toronto, North York, York, Etobicoke and Scarborough, and the former borough of East York). We combined the two areas to obtain sufficient sample size to construct life tables for the 20 sub-populations, each requiring death data by 5 -year age group. Both areas have about the same percentage of immigrants, and both are in the same labour market area (the census metropolitan area of Toronto).

\section{Definitions}

Income adequacy quintiles. To construct income adequacy quintiles (fifths of the population), a previous study ${ }^{5}$ determined the total pre-tax, post-transfer income from all sources for each economic family or unattached individual in the entire non-institutional census population. Then, for each family size and community size group, it calculated the ratio of total income to the 1991 low income cut-off. Within each census metropolitan area, census agglomeration and rural areas of each province, the population of all ages, both sexes together, was then ranked according to this ratio and divided into fifths.

Immigrant. In this analysis, the term "immigrant" refers to people who were not Canadian citizens by birth. It includes all persons who were or had ever been landed immigrants in Canada or who had the status of non-permanent residents as reported in the 1991 census. Some immigrants had resided in Canada for a number of years, while others had only arrived recently; virtually all were born outside of Canada.

Non-immigrant. In this analysis, "nonimmigrant" refers to people who were Canadian citizens by birth. Almost all non-immigrants were born in Canada.

\section{Analytical techniques}

Mortality analyses. For each member of the cohort, person-days of follow-up were calculated from the beginning of the study (4 June 1991) to the date of death, emigration (known for 1991 only) or end of the study (31 December 2001). Person-days of follow-up were then divided by 365.25 to get person-years at risk.

Abridged period life tables for each sex and quintile, plus corresponding standard errors and $95 \%$ confidence intervals (CIs) were calculated according to Chiang's method. ${ }^{16}$ These calculations were done after age was transformed from age at baseline to age at the beginning of each year of follow-up, and deaths and person-years at risk were calculated separately for each year (or partial year) of follow-up. Deaths and person-years at risk were then pooled by 5-year age groups at the beginning of each year of follow-up, before the calculation of the life tables. ${ }^{5}$

\section{Results}

\section{Cohort members and deaths during the follow-up period}

At cohort inception a total of 287500 cohort members lived in either the City of Toronto (220 400) or Region of Peel (67 100), of whom $53 \%$ were immigrants. Of those eligible cohort members, 25648 died during the follow-up period (12 134 immigrants, 13514 non-immigrants).

For all cohort members, as well as for immigrants and non-immigrants of each sex, Table 1 shows the number of cohort members in each income quintile, together with the corresponding person-years at risk and number of deaths. Mainly because cohort members had to be linked to tax filer data in order to be followed for mortality, and people of higher income were more likely to be tax filers, fewer than $20 \%$ of the cohort were in the lowest income quintile, and more than $20 \%$ were in the highest.

\section{Socio-economic characteristics of each income quintile}

For all cohort members, immigrants and non-immigrants of both sexes combined, Table 2 shows various socio-economic characteristics for each income adequacy quintile at baseline, expressed as a percentage of the total number of cohort members in each quintile. Since all the characteristics shown were clearly graded by income, we only note the highest and lowest values in each series.

Compared to cohort members in the highest income quintile, those in the lowest income quintile were much more likely to have not graduated from high school (46\% versus $16 \%$ ) and to have government transfers as their major source of income ( $41 \%$ versus $2 \%)$; further, they were less likely to have received a university degree (10\% versus $39 \%$ ).

Nearly $100 \%$ of immigrants, but fewer than $1 \%$ of non-immigrants, were foreign-born. The proportion of foreign-born ranged from $38 \%$ in the highest income quintile to $66 \%$ in the lowest income quintile. The 
TABLE 1

Cohort members, person-years at risk, and deaths during the study period, by income adequacy quintile and sex, by immigrant status, City of Toronto and Region of Peel, 1991-2001 (non-institutionalized people aged 25 and over at baseline)

\begin{tabular}{|c|c|c|c|c|c|c|}
\hline \multirow[b]{2}{*}{$\begin{array}{l}\text { Immigrant status } \\
\text { Income quintile }\end{array}$} & \multicolumn{3}{|c|}{ Men } & \multicolumn{3}{|c|}{ Women } \\
\hline & Cohort members & $\begin{array}{c}\text { Person-years } \\
\text { at risk }\end{array}$ & Deaths & Cohort members & $\begin{array}{c}\text { Person-years } \\
\text { at risk }\end{array}$ & Deaths \\
\hline \multicolumn{7}{|c|}{ Immigrants $^{\mathrm{a}}$ and non-immigrants } \\
\hline Quintile 1 (lowest) & 24000 & 232550 & 3873 & 31000 & 307590 & 4125 \\
\hline Quintile 2 & 28700 & 285830 & 3286 & 31300 & 319980 & 2314 \\
\hline Quintile 3 & 29100 & 294830 & 2623 & 29800 & 306080 & 1779 \\
\hline Quintile 5 (highest) & 28600 & 290690 & 2298 & 27000 & 278760 & 1476 \\
\hline \multicolumn{7}{|l|}{ Immigrants $^{a}$} \\
\hline Total, all income quintiles & 75100 & 756830 & 7212 & 76100 & 780790 & 4922 \\
\hline Quintile 1 (lowest) & 16400 & 162030 & 2140 & 19600 & 197530 & 1885 \\
\hline Quintile 2 & 17900 & 180080 & 1766 & 18300 & 188510 & 1066 \\
\hline Total, all income quintiles & 64600 & 645270 & 7239 & 71700 & 727360 & 6275 \\
\hline Quintile 1 (lowest) & 7600 & 70510 & 1733 & 11400 & 110040 & 2240 \\
\hline Quintile 2 & 10800 & 105760 & 1520 & 13000 & 131450 & 1248 \\
\hline Quintile 3 & 13100 & 132020 & 1304 & 14400 & 147560 & 991 \\
\hline Quintile 4 & 15600 & 157840 & 1263 & 15700 & 161680 & 847 \\
\hline Quintile 5 (highest) & 17600 & 179150 & 1419 & 17100 & 176600 & 949 \\
\hline
\end{tabular}

Source: Special tabulations from the 1991-2001 Canadian census mortality follow-up study. ${ }^{5}$

Note: The number of cohort members and person-years at risk were rounded independently (to the nearest 100 , or the nearest 10 , respectively).

${ }^{\text {a }}$ Foreign-born, including non-permanent residents.

TABLE 2

Characteristics of cohort members (immigrants and non-immigrants combined) within each income adequacy quintile, City of Toronto and Region of Peel, at cohort inception, 1991

\begin{tabular}{|c|c|c|c|c|c|c|c|c|}
\hline \multicolumn{9}{|c|}{ Percentage of quintile total, \% } \\
\hline Income quintile & Total & Foreign-born $^{a}$ & $\begin{array}{c}\text { Recent } \\
\text { immigrants }\end{array}$ & $\begin{array}{c}\text { Visible } \\
\text { minorities }^{c}\end{array}$ & $\begin{array}{c}\text { Less than high } \\
\text { school } \\
\text { graduation }\end{array}$ & $\begin{array}{l}\text { University } \\
\text { degree }\end{array}$ & $\begin{array}{l}\text { Government } \\
\text { transfers }^{\mathrm{d}}\end{array}$ & Aboriginale $^{\mathrm{e}}$ \\
\hline Total, all quintiles & 100.0 & 52.8 & 10.7 & 24.0 & 31.2 & 19.8 & 14.5 & 0.8 \\
\hline Quintile 1 (lowest) & 100.0 & 65.7 & 23.0 & 35.2 & 46.4 & 10.4 & 41.0 & 1.0 \\
\hline Quintile 2 & 100.0 & 60.5 & 14.1 & 29.5 & 37.5 & 12.2 & 15.9 & 0.8 \\
\hline Quintile 3 & 100.0 & 53.5 & 8.7 & 24.0 & 31.1 & 16.1 & 8.7 & 0.8 \\
\hline Quintile 4 & 100.0 & 46.4 & 5.1 & 18.4 & 25.1 & 22.1 & 5.3 & 0.7 \\
\hline Quintile 5 (highest) & 100.0 & 37.9 & 2.8 & 12.8 & 16.0 & 38.8 & 2.4 & 0.6 \\
\hline
\end{tabular}

Source: Special tabulations from the 1991-2001 Canadian census mortality follow-up study. ${ }^{5}$

${ }^{\text {a }}$ Almost $100 \%$ of immigrants, but less than $1 \%$ of non-immigrants, were foreign born.

${ }^{\mathrm{b}}$ Immigrants in the period 1986-1991.

c In Canada, the term "visible minorities" does not include Aboriginal peoples; $43 \%$ of immigrants and 3\% of non-immigrants were visible minorities.

${ }^{d}$ Percentage of cohort members whose major source of income was from government transfer payments.

e Aboriginal ancestry or Registered Indian; almost all (96\%) were non-immigrants.

proportion of recent immigrants (1986-1991) ranged from $3 \%$ in the highest income quintile to $23 \%$ in the lowest.

In Canada, the term "visible minorities" does not include Aboriginal peoples. ${ }^{5}$ In our Toronto-Peel cohort, the proportion of visible minorities ranged from $13 \%$ in the highest income quintile to $35 \%$ in the lowest. Almost all Aboriginal cohort members (96\%) were non-immigrants, but the proportion of Aboriginal people was low $(\leq 1 \%)$ in all quintiles.
Table 3 shows the overall percentages of each characteristic for immigrants and non-immigrants separately, plus the percentages for immigrant and nonimmigrants within each income quintile. Overall, one-fifth (20\%) of immigrants were recent immigrants (1986-1991), but that 
TABLE 3

Characteristics of cohort members, showing immigrants and non-immigrants separately within each income adequacy quintile, City of Toronto and Region of Peel, at cohort inception, 1991 (percentage of row total for immigrants and non-immigrants)

\begin{tabular}{|c|c|c|c|c|c|c|c|c|c|c|c|c|}
\hline \multirow[b]{2}{*}{ Income quintile } & \multicolumn{2}{|c|}{ Recent immigrants $^{\mathrm{a}}$} & \multicolumn{2}{|c|}{ Visible minorities $^{b}$} & \multicolumn{2}{|c|}{$\begin{array}{c}\text { Less than high school } \\
\text { graduation }\end{array}$} & \multicolumn{2}{|c|}{ University degree } & \multicolumn{2}{|c|}{$\begin{array}{l}\text { Government } \\
\text { transfers }^{c}\end{array}$} & \multicolumn{2}{|c|}{ Aboriginald $^{d}$} \\
\hline & Immigrant & $\begin{array}{l}\text { Non- } \\
\text { immigrant }\end{array}$ & Immigrant & $\begin{array}{c}\text { Non- } \\
\text { immigrant }\end{array}$ & Immigrant & $\begin{array}{c}\text { Non- } \\
\text { immigrant }\end{array}$ & Immigrant & $\begin{array}{c}\text { Non- } \\
\text { immigrant }\end{array}$ & Immigrant & $\begin{array}{c}\text { Non- } \\
\text { immigrant }\end{array}$ & Immigrant & $\begin{array}{c}\text { Non- } \\
\text { immigrant }\end{array}$ \\
\hline Total, all quintiles & 20.3 & 0.0 & 43.1 & 2.8 & 36.4 & 25.5 & 16.3 & 23.7 & 16.1 & 12.6 & 0.1 & 1.6 \\
\hline Quintile 1 (lowest) & 35.2 & 0.0 & 52.1 & 3.3 & 45.7 & 47.7 & 10.8 & 9.8 & 36.6 & 49.2 & 0.0 & 2.7 \\
\hline Quintile 2 & 23.3 & 0.0 & 47.1 & 2.8 & 40.5 & 32.9 & 11.8 & 13.0 & 15.5 & 16.4 & 0.0 & 1.9 \\
\hline Quintile 3 & 16.4 & 0.0 & 42.7 & 2.6 & 35.7 & 25.8 & 14.5 & 17.9 & 9.7 & 7.6 & 0.1 & 1.6 \\
\hline Quintile 4 & 11.0 & 0.0 & 36.5 & 2.8 & 30.7 & 20.2 & 19.2 & 24.6 & 6.8 & 3.9 & 0.1 & 1.3 \\
\hline Quintile 5 (highest) & 7.6 & 0.0 & 29.7 & 2.6 & 21.6 & 12.6 & 33.0 & 42.4 & 3.5 & 1.7 & 0.1 & 0.9 \\
\hline
\end{tabular}

Source: Special tabulations from the 1991-2001 Canadian census mortality follow-up study. ${ }^{5}$

${ }^{a}$ Immigrants in the period 1986-1991.

${ }^{\mathrm{b}}$ In Canada, the term "visible minorities" does not include Aboriginal people; $43 \%$ of immigrants and 3\% of non-immigrants were visible minorities.

${ }^{c}$ Percentage of cohort members whose major source of income was from government transfer payments.

${ }^{\mathrm{d}}$ Aboriginal ancestry or Registered Indian; almost all (96\%) were non-immigrants.

varied from over one-third (35\%) of the lowest income quintile, to less than one-tenth (8\%) of the highest income quintile. Not unexpectedly immigrants were far more likely than non-immigrants to be visible minorities ( $43 \%$ versus $3 \%$ ), though within immigrants, the proportion of visible minorities varied from over half in the lowest income quintile (52\%), to less than one-third $(30 \%)$ in the highest. Over one-third of immigrants had less than high school graduation (36\%), compared to about one-quarter of non-immigrants (26\%). Compared to non-immigrants, immigrants were less likely to have a university degree (16\% versus $24 \%$ ), and somewhat more likely to have government transfers as their major source of income (16\% versus $13 \%$ ). Among non-immigrants, the percentage of Aboriginal people was 3\% in the lowest income quintile, compared to less than $1 \%$ in the highest.

\section{Disparities in remaining years of life at age 25 years}

Remaining years of life expectancy at age 25 years (conditional on surviving to age 25 years) are shown in Table 4 . For all cohort members of each sex in the study area (including both immigrants and nonimmigrants), there was a clear gradient across the income quintiles, with higher life expectancy in each successively richer quintile. The difference in remaining life expectancy between the lowest and highest income quintiles was 5.3 years for men and 3.3 years for women.
For non-immigrants, the income for both men and women. The gap gradient in remaining life expectancy between the lowest and the highest was steeper, with a very clear stepwise income quintiles was 9.8 years for men progression across the income quintiles and 7.4 years for women.

\section{TABLE 4}

Remaining life expectancy at age 25 years (conditional on surviving to age 25 years), by income adequacy quintile and sex, by immigrant status, City of Toronto and Region of Peel, 1991-2001

\begin{tabular}{|c|c|c|}
\hline $\begin{array}{l}\text { Immigrant status } \\
\text { Income quintile }\end{array}$ & $\begin{array}{c}\text { Men } \\
\text { Years }(95 \% \mathrm{Cl})\end{array}$ & $\begin{array}{c}\text { Women } \\
\text { Years }(95 \% \mathrm{Cl})\end{array}$ \\
\hline \multicolumn{3}{|c|}{ Immigrants ${ }^{\mathrm{a}}$ and non-immigrants } \\
\hline Total, all quintiles & $53.7 \quad(53.5,53.9)$ & $59.3(59.1,59.5)$ \\
\hline Quintile 1 (lowest) & $50.6(50.2,51.0)$ & $57.1(56.7,57.5)$ \\
\hline Quintile 2 & $53.0 \quad(52.6,53.4)$ & $59.2 \quad(58.8,59.6)$ \\
\hline Quintile 3 & $54.0 \quad(53.6,54.4)$ & $59.7 \quad(59.2,60.1)$ \\
\hline Quintile 4 & $55.0 \quad(54.6,55.4)$ & $60.6(60.2,61.1)$ \\
\hline Quintile 5 (highest) & $56.0 \quad(55.5,56.4)$ & $60.4 \quad(60.0,60.9)$ \\
\hline Difference Q5-Q1 & $5.3 \quad(4.7, \quad 5.9)$ & $3.3 \quad(2.7,3.9)$ \\
\hline \multicolumn{3}{|l|}{ Immigrants ${ }^{\mathrm{a}}$} \\
\hline Total, all quintiles & $55.4 \quad(55.1,55.6)$ & $60.9 \quad(60.6,61.1)$ \\
\hline Quintile 1 (lowest) & $53.8 \quad(53.3,54.3)$ & $60.3(59.8,60.8)$ \\
\hline Quintile 2 & $55.0 \quad(54.5,55.5)$ & $60.7 \quad(60.1,61.2)$ \\
\hline Quintile 3 & $55.6 \quad(55.0,56.1)$ & $60.9 \quad(60.3,61.5)$ \\
\hline Quintile 4 & $56.4(55.7,57.0)$ & $61.2(60.5,61.9)$ \\
\hline Quintile 5 (highest) & $57.6 \quad(56.9,58.3)$ & $61.1 \quad(60.3,61.8)$ \\
\hline Difference Q5-Q1 & $3.8 \quad(3.0,4.7)$ & $0.8 \quad(-0.1,1.7)$ \\
\hline \multicolumn{3}{|l|}{ Non-immigrants } \\
\hline Total, all quintiles & $51.7 \quad(51.4,52.0)$ & $57.6(57.4,57.9)$ \\
\hline Quintile 1 (lowest) & $45.1 \quad(44.4,45.9)$ & $52.5(51.8,53.2)$ \\
\hline Quintile 2 & $49.7 \quad(49.0,50.4)$ & $57.3(56.7,58.0)$ \\
\hline Quintile 3 & $51.7 \quad(51.1,52.3)$ & $58.4(57.7,59.0)$ \\
\hline Quintile 4 & $53.6(53.0,54.1)$ & $60.1 \quad(59.4,60.7)$ \\
\hline Quintile 5 (highest) & $55.0 \quad(54.5,55.5)$ & $60.0 \quad(59.4,60.5)$ \\
\hline Difference Q5-Q1 & $9.8 \quad(8.9,10.7)$ & $7.4 \quad(6.5,8.3)$ \\
\hline
\end{tabular}

Source: Special tabulations from the 1991-2001 Canadian census mortality follow-up study. ${ }^{5}$

Abbreviations: $\mathrm{Cl}$, confidence interval; $\mathrm{Q}$, quintile.

${ }^{a}$ Foreign-born, including non-permanent residents. 
For immigrants, the income gradient in remaining life expectancy was markedly less steep. The gap between the highest and lowest quintiles was 3.8 years for immigrant men and 0.8 years for immigrant women.

Note that within each income quintile and for both sexes, the remaining life expectancy of immigrants always exceeded that of non-immigrants. However, the differences between immigrants and non-immigrants were smallest in the highest income quintile (2.6 years for men, 1.1 years for women) and largest in the lowest (8.7 years for men, 7.8 years for women).

\section{Disparities in the probability of survival to age 75 years}

The probability of surviving to age 75 years (conditional on surviving to age 25 years) is shown in Table 5 . As with life expectancy at age 25 years, the proportion of men and women expected to survive to age 75 years increased in each successively higher income quintile, for all cohort members as well as for both immigrants and nonimmigrants. However, the disparities were much more striking for non-immigrants.

For all cohort members of each sex there was a clear gradient across the income quintiles, with higher probability of survival to age 75 years in each successively richer quintile. Among men, the probability of survival to age 75 years was $57 \%$ in the lowest income quintile and $74 \%$ in the highest (a difference of 17 percentage points). Among women, the probability of survival to age 75 years ranged from $73 \%$ in the lowest income quintile to $84 \%$ in the highest (a difference of 10 percentage points).

For non-immigrant men, the probability of survival to age 75 years was $40 \%$ in the lowest income quintile and $73 \%$ in the highest (a difference of 33 percentage points). For immigrant men, the probability of survival to age 75 years was $67 \%$ for those in the lowest income quintile and $76 \%$ for those in the highest (a difference of 9 percentage points).

For non-immigrant women, the probability of survival to age 75 years ranged from $61 \%$ in the lowest income quintile to $82 \%$ in

TABLE 5

Probability of survival to age 75 years (conditional on surviving to age 25 years), by income adequacy quintile and sex, by immigrant status, City of Toronto and Region of Peel, 1991-2001

\begin{tabular}{|c|c|c|c|c|}
\hline \multirow{2}{*}{$\begin{array}{l}\text { Immigrant status } \\
\text { Income quintile }\end{array}$} & \multicolumn{4}{|c|}{ \% Probability (95\% CI) } \\
\hline & & Men & & Women \\
\hline \multicolumn{5}{|c|}{ Immigrants and non-immigrants } \\
\hline Total, all quintiles & 66.9 & $(66.3,67.5)$ & 80.1 & $(79.5,80.6)$ \\
\hline Quintile 1 (lowest) & 57.0 & $(55.5,58.5)$ & 73.3 & $(72.0,74.5)$ \\
\hline Quintile 2 & 64.1 & $(62.7,65.5)$ & 79.5 & $(78.4,80.7)$ \\
\hline Quintile 3 & 67.3 & $(66.0,68.7)$ & 81.8 & $(80.6,82.9)$ \\
\hline Quintile 4 & 69.5 & $(68.2,70.8)$ & 82.9 & $(81.7,84.1)$ \\
\hline Quintile 5 (highest) & 74.1 & $(72.9,75.4)$ & 83.6 & $(82.4,84.7)$ \\
\hline Difference Q5-Q1 & 17.2 & $(15.2,19.1)$ & 10.3 & $(8.6,12.0)$ \\
\hline \multicolumn{5}{|l|}{ Immigrants $^{a}$} \\
\hline Total, all quintiles & 71.5 & $(70.7,72.3)$ & 83.6 & $(82.9,84.3)$ \\
\hline Quintile 1 (lowest) & 67.2 & $(65.4,69.1)$ & 81.0 & $(79.5,82.4)$ \\
\hline Quintile 2 & 69.3 & $(67.6,71.0)$ & 82.4 & $(80.9,83.8)$ \\
\hline Quintile 3 & 72.3 & $(70.6,74.0)$ & 85.1 & $(83.7,86.6)$ \\
\hline Quintile 4 & 73.1 & $(71.3,74.9)$ & 85.3 & $(83.7,86.9)$ \\
\hline Quintile 5 (highest) & 75.8 & $(74.0,77.7)$ & 85.4 & $(83.6,87.2)$ \\
\hline Difference Q5-Q1 & 8.6 & $(6.0,11.2)$ & 4.4 & $(2.1,6.7)$ \\
\hline \multicolumn{5}{|l|}{ Non-immigrants } \\
\hline Total, all quintiles & 61.0 & $(60.0,62.0)$ & 76.0 & $(75.2,76.9)$ \\
\hline Quintile 1 (lowest) & 39.7 & $(37.3,42.2)$ & 60.9 & $(58.6,63.1)$ \\
\hline Quintile 2 & 54.5 & $(52.0,56.9)$ & 75.1 & $(73.2,77.1)$ \\
\hline Quintile 3 & 59.7 & $(57.5,61.9)$ & 77.6 & $(75.8,79.5)$ \\
\hline Quintile 4 & 65.1 & $(63.1,67.2)$ & 80.2 & $(78.5,82.0)$ \\
\hline Quintile 5 (highest) & 72.9 & $(71.2,74.6)$ & 82.3 & $(80.8,83.9)$ \\
\hline Difference Q5-Q1 & 33.1 & $(30.2,36.1)$ & 21.5 & $(18.7,24.2)$ \\
\hline
\end{tabular}

Source: Special tabulations from the 1991-2001 Canadian census mortality follow-up study. ${ }^{5}$

Abbreviations: $\mathrm{Cl}$, confidence interval; $\mathrm{Q}$, quintile.

${ }^{a}$ Foreign-born, including non-permanent residents.

the highest (a difference of 21 percentage points). For immigrant women, the probability of survival to age 75 years ranged from $81 \%$ in the lowest income quintile to $85 \%$ in the highest (a difference of 4 percentage points).

Note that in each income quintile and for both sexes, the probability of survival to age 75 years for immigrants always exceeded that for non-immigrants. However, the difference between immigrants and nonimmigrants was largest in the lowest income quintile (28 percentage points for men, 20 percentage points for women), and smallest in the highest (3 percentage points for both men and women).

\section{Discussion}

Results from this study clearly show that for both men and women in the City of Toronto and Region of Peel, remaining life expectancy at age 25 years and probability of survival to age 75 years differed substantially across income quintiles. That was not surprising, though data with individual and family-level income were required to demonstrate it. We also found that the disparities in mortality by income were much greater when the analysis was restricted to non-immigrants. Moreover, within each income quintile, immigrants had more favourable results compared to non-immigrants, but the immigrant advantage was particularly marked within the lowest income quintiles. Neither the greater disparities in mortality by income among non-immigrants, nor the greater survival advantage for immigrants in lower income groups has previously been reported for Canada.

The failure of our previous small-area based study to detect differences in life expectancy across neighbourhood income quintiles was likely because of considerable confounding due to the presence of a 
much higher than average proportion of low-mortality immigrants (and especially of recent immigrants, with particularly low mortality) within otherwise highmortality low-income neighbourhoods, as well as non-differential misclassification due to the use of census tract averages rather than individual and family income.

In terms of both remaining life expectancy and probability of survival to age 75 years, these results not only confirm previous work by showing substantial disparities by income overall, but they also reveal that the income gradient in mortality was much steeper among non-immigrants compared to immigrants.

The healthy immigrant effect presumably reflects a high degree of self-selection. First, people are less likely to try to immigrate if they are unhealthy. Second, the immigration process requires that immigrants undergo medical screening to enter Canada, and immigrants are selected based on their wealth, employability, ${ }^{9}$ education, and language abilities. ${ }^{17}$ Third, unhealthy behaviours such as smoking, heavy drinking and poor diet tend to be less common among immigrants compared to non-immigrants. ${ }^{9,18}$

Research has shown that immigrants in general tend to enjoy better health than do non-immigrants. This has been observed for a variety of chronic diseases as well as disability, dependency, life expectancy and disability-free life expectancy. ${ }^{17-24}$ Although immigrants are usually in excellent health upon arrival in Canada, over time their health status tends to converge toward that of the Canadianborn population. ${ }^{7,25}$ In particular, research has shown that recent immigrants have lower mortality rates compared to longerterm immigrants. ${ }^{5}$ The larger gap between immigrants and non-immigrants that we observed in the lower income quintiles compared to the higher income quintiles appears to be related, at least in part, to the higher proportion of recent immigrants in the lower income quintiles. Future studies with adequate power should attempt to control for such confounding.

\section{Limitations}

The 1991-2001 Canadian census mortality follow-up study excluded people who were missed by the 1991 census (about $3.4 \%$ of the total population). The missed individuals were more likely to be young, mobile, low income, of Aboriginal ancestry ${ }^{26}$ or homeless. In addition, people residing in long-term care facilities, seniors' residences or prisons (who were not enumerated by a long-form questionnaire), and non-tax filers in both the 1990 and 1991 tax years (as this information was needed for the linkage) were excluded from the cohort. As a result, the entire cohort across Canada had one year longer remaining life expectancy for men, and two years longer remaining life expectancy for women when compared to life tables for the entire population of Canada. $^{5}$

Information on family income and place of residence was only available at baseline. Since these characteristics are expected to change over time, it would have been preferable to have income and place of residence for each year of follow-up.

Because this analysis was restricted to the City of Toronto and Region of Peel, our cohort had insufficient numbers to allow us to further distinguish between recent and long-term immigrants, except in terms of population characteristics. Future analyses using the entire cohort should both do so and examine other factors such as country or region of origin and visible minority status to better understand the trends by income that we see in these data. ${ }^{27}$

\section{Conclusion}

Our results highlight the importance of using individual and family level data when analysing income disparities in health outcomes in a population as diverse as that of Canada's largest metropolitan area. It also shows the importance of taking account of both immigrant status and recency of immigration in understanding the relationship between income and two basic health outcomes-remaining life expectancy at age 25 years and the probability of survival to age 75 years. This is especially important for areas such as the City of Toronto and Region of Peel, which have a very high proportion of immigrants, including many recent immigrants.

While vital statistics death and birth registrations collect information on the birthplace of the decedent, or of the mother, that information is often overlooked when data are compiled and analysed. In other administrative datasets, such as cancer registries and hospital morbidity data, no information is collected on place of birth. This study demonstrates the importance of collecting and analysing this type of data, not just for understanding the relationships between immigration and health (though that is important), but also for clarifying the extent and nature of socio-economic disparities in health more generally.

Future work could investigate ways of including the morbidity and mortality experience of institutional residents-the most disabled segment of the populationas well as that of people aged less than 25 years, to get a more comprehensive picture of morbidity and mortality in relation to socio-economic position. ${ }^{3}$ Analyses examining causes of death within each of the quintiles would further enhance knowledge with regard to potential prevention efforts intended to reduce health disparities related to socio-economic circumstances.

\section{Acknowledgements}

Major funding for the creation of the 1991-2001 Canadian census mortality follow-up study, upon which this work was based, was provided by the Canadian Population Health Initiative, part of the Canadian Institute for Health Information.

We are grateful to Canada's provincial and territorial registrars of vital statistics, who provided the death data used in this study; to Statistics Canada, which conducted the 1991 census; and to the people of Canada, whose answers to the long-form census questionnaire provided the basis for these analyses. 


\section{Appendix}

TABLE A

Remaining life expectancy at age 25, by neighbourhood income quintile, Peel Region, 2005

\begin{tabular}{lcc}
$\begin{array}{l}\text { Neighbourhood } \\
\text { income quintile }\end{array}$ & Men & Years remaining \\
\hline Quintile 1 (lowest) & 56.6 & Women \\
Quintile 2 & 57.3 & 61.1 \\
Quintile 3 & 56.8 & 60.6 \\
Quintile 4 & 57.3 & 61.0 \\
Quintile 5 (highest) & 57.0 & 59.9 \\
Difference: Q5-Q1 & +0.4 & 59.4 \\
\hline
\end{tabular}

Source: Stratton J et al. $2010^{28}$. Special tabulations based on Ontario Mortality Database 2005, HELPS (Health Planning System), Ministry of Health Promotion; and 2006 census tract profiles, Statistics Canada.

Note: Neighbourhood income quintiles based on census tract proportion of people whose economic family or individual income was less than the Statistics Canada low income cut-off for the applicable family size and community size group.

\section{References}

1. Wolfson MC, Kaplan G, Lynch J, Ross N, Backlund E. Relation between income inequality and mortality: empirical demonstration. West J Med. 2000 Jan;172(1):22-4.

2. Wilkins R, Berthelot JM, Ng E. Trends in mortality by neighbourhood income in urban Canada from 1971 to 1996 . Health Rep. 2002;13 (suppl):1-27.

3. McIntosh $\mathrm{CN}$, Finès $\mathrm{P}$, Wilkins $\mathrm{R}$, Wolfson MC. Income disparities in healthadjusted life expectancy for Canadian adults, 1991 to 2001. Health Rep. 2009 Dec;20(4):55-64.

4. Pampalon R, Hamel D, Gamache P. A comparison of individual and area-based socio-economic data for monitoring social inequalities in health. Health Rep. 2009 Sep;20(3):85-94.

5. Wilkins R, Tjepkema M, Mustard C, Choinière R. The Canadian census mortality follow-up study, 1991 through 2001. Health Rep. 2008 Sep;19(3):25-43.

6. Lynch J, Harper S, Kaplan GA, Davey Smith G. Associations between income inequality and mortality among US states: the importance of time period and source of income data. Am J Public Health. 2005 Aug;95(8):1424-30.
14. Ng E; Longitudinal Health and Administrative Data Research Team. Insights into the healthy immigrant effect: mortality by period of immigration and birthplace. Health Analysis Division Working Paper Series. Ottawa (ON): Statistics Canada; 2011 September. 16 pp. [Statistics Canada, Catalogue No.: 82-622-XIE2011008]

15. Ng E. The healthy immigrant effect and mortality rates. Health Rep. 2011;22(4):1-5.

16. Chiang CL. The life table and its applications. Malabar (FL): Robert E Krieger Publ Co; 1984.

17. Hyman I. Immigration and health: reviewing evidence of the healthy immigrant effect in Canada. CERIS Working Paper No. 55. Toronto (ON): Joint Centre of Excellence for Research on Immigration and Settlement; 2007 Apr.

18. Pérez CE. Health status and health behaviour among immigrants. Health Rep. 2002;13 (suppl):1-12.

19. Singh GK, Miller BA. Health, life expectancy, and mortality patterns among immigrant populations in the United States. Can J Public Health. 2004 May-Jun;95(3):14-21.

9. Chen J, Wilkins R, Ng E. Health expectancy by immigrant status, 1986 and 1991. Health Rep. 1996 Winter;8(3):29-38.

10. DesMeules M, Gold J, McDermott S, Cao Z, Payne J, Lafrance B, et al. Disparities in mortality patterns among Canadian immigrants and refugees, 1980-1998: results of a national cohort study. J Immigr Health 2005 Oct; $7(4): 221-32$

11. Trovato F, Odynak D. Sex differences in life expectancy in Canada: immigrant and native-born populations. J Biosoc Sci. 2011 May;43(3):353-67.

12. Saposnik G, Redelmeier DA, Lu H, Fuller-Thomson E, Lonn E, Ray JG. Myocardial infarction associated with recency of immigration to Ontario. QJM. 2010 Apr;103(4):253-8.

13. Pampalon R, Hamel D, Gamache P. Health inequalities, deprivation, immigration and aboriginality in Canada: a geographic perspective. Can J Public Health. 2010 Nov-Dec;101(6):470-4.
20. DesMeules M, Gold J, Kazanjian A, Manuel D, Payne J, Vissandée B, McDermott S, Mao Y. New approaches to immigrant health assessment. Can J Public Health. 2004 May-Jun;95(3):22-6.

21. Singh GK, Siahpush M. All-cause and cause-specific mortality of immigrants and native born in the United States. Am J Public Health. 2001 Mar;91(3):392-9.

22. Singh GK, Hiatt RA. Trends and disparities in socioeconomic and behavioural characteristics, life expectancy, and cause-specific mortality of native-born and foreign-born populations in the United States, 1979-2003. Int J Epidemiol. 2006 Aug;35(4):903-19.

23. Hajat A, Blakely $T$, Dayal S, Jatrana S. Do New Zealand's immigrants have a mortality advantage? Evidence from the New Zealand Census-Mortality Study. Eth Health. 2010 Oct;15(5):531-47. 
24. Singh GK, Siahpush M. Ethnic-immigrant differentials in health behaviors, morbidity and cause-specific mortality in the United States: an analysis of two national databases. Hum Biol. 2002 Feb;74(1):83-109.

25. Newbold KB. Self-rated health within the Canadian immigrant population: risk and the healthy immigrant effect. Soc Sci Med. 2005 Mar;60(6):1359-70.

26. Statistics Canada. Coverage. 1991 Census Technical Reports; Reference Products Series. Ottawa (ON): Minister of Industry, Science and Technology; 1994. [Statistics Canada, Catalogue No.: 92-341].

27. McDonald JT, Kennedy S. Insights into the 'healthy immigrant effect': health status and health service use of immigrants to Canada. Soc Sci Med. 2004 Oct;59(8):1613-27.

28. Stratton J, Mowat DL, Wong KP. Remaining life expectancy at age 25 , by neighbourhood income quintile, Peel Region, 2005. Brampton (ON): Region of Peel Public Health, 2010. 